Research Article

\title{
Chemical and Pharmacological Evaluation of Hulls of Prunus dulcis Nuts
}

\author{
Muhammad Nasimullah Qureshi $\mathbb{D}^{1},{ }^{1}$ Sodik Numonov, ${ }^{2,3,4}$ and Haji Akber Aisa $\mathbb{D I}^{2,5}$ \\ ${ }^{1}$ Department of Chemistry, University of Swabi, Anbar, Pakistan \\ ${ }^{2}$ Key Laboratory of Plant Resources and Chemistry in Arid Regions, Xinjiang Technical Institute of Physics and Chemistry, \\ Chinese Academy of Sciences, Urumqi 830011, China \\ ${ }^{3}$ Research Institution "Chinese-Tajik Innovation Center for Natural Products", Ayni St. 299/2, Dushanbe 734063, Tajikistan \\ ${ }^{4}$ Center for Research in Innovative Technologies, Academy of Sciences of the Republic of Tajikistan, Ayni St. 299/3, \\ Dushanbe 734063, Tajikistan \\ ${ }^{5}$ Key Laboratory of Xinjiang Indigenous Medicinal Plants Resource Utilization, \\ Xinjiang Technical Institute of Physics and Chemistry, Chinese Academy of Sciences, Urumqi 830011, China
}

Correspondence should be addressed to Muhammad Nasimullah Qureshi; mnasimuq@yahoo.com and Haji Akber Aisa; haji@ms.xjb.ac.cn

Received 23 June 2019; Revised 6 October 2019; Accepted 31 October 2019; Published 22 November 2019

Academic Editor: Günther K. Bonn

Copyright (c) 2019 Muhammad Nasimullah Qureshi et al. This is an open access article distributed under the Creative Commons Attribution License, which permits unrestricted use, distribution, and reproduction in any medium, provided the original work is properly cited.

\begin{abstract}
Researchers have shown that the almond hulls, normally wasted after utilization of nuts, contain a number of biologically active compounds based on which the present study has been carried out. Focus is placed on the mass spectrometric determination of the analytes along with the estimation of total polyphenolic and total flavonoid contents in the $70 \%$ ethanol extract. After partitioning the $70 \%$ ethanol extract in hexane, chloroform, ethyl acetate, $n$-butanol, and water, all the extracts were evaluated for their antioxidant, antidiabetic, and antimicrobial activities. The results delivered total polyphenolic compounds as gallic acid equivalents $(1 \% \mathrm{w} / \mathrm{w})$ of the dried extract and total flavonoid contents as quercetin equivalents $(0.2 \% \mathrm{w} / \mathrm{w})$ of the dried extract. Mass spectrometric analysis resulted in the identification of 15 compounds containing various derivatives of (epi)catechin, chlorogenic acid, kaempferol, isorhamnetin and their glycosides, ursolic acid, amygdalactone, and benzoic acid derivatives. Antioxidant activity experiments showed that highest activity was found in $n$-butanol extract among the studied samples with $\mathrm{IC}_{50}$ value as $76.04 \mu \mathrm{g} / \mathrm{ml}$, while hexane and chloroform extracts were active against the PTP1B enzyme with $\mathrm{IC}_{50} \mathrm{values} 9.66 \mu \mathrm{g} / \mathrm{ml}$ and $37.95 \mu \mathrm{g} / \mathrm{ml}$, respectively. Hexane and chloroform fractions were active against Staphylococcus aureus with the zone of inhibition diameter $9 \mathrm{~mm}$ and $12 \mathrm{~mm}$, respectively.
\end{abstract}

\section{Introduction}

Hulls and peels from the fruits and vegetables are being considered as a source for getting beneficial products such as phenolic compounds, which have proven antioxidant activity along with other pharmacological activities [1-4]. Almond nuts have been used since long for their various nutritional and pharmacological values as snacks or as a constituent for manufacturing processed food [2]. Almond hulls are removed for the utilization of nuts and are wasted without any use or used as feedstock in few cases.
Researchers have shown that almond hulls are valuable byproducts of almond nuts, which contain a number of biologically active compounds such as triterpenoids, phenolic compounds, and their derivatives. Among the triterpenoids, betulinic acid, oleanolic acid, and ursolic acid have been identified, constituting about $1 \%$ of the hulls [5]. Flavan-3-ols, cinnamic acid, and hydroxybenzoic acid have been reported in almond hulls $[1,5,6]$. Glycosylated flavonols such as rhamnetin or isorhamnetin glycosides, quercetin glycosides, kaempferol glycosides $[1,7]$ and chlorogenic acid and their derivatives [5] have been 
identified in the extracts of almond hulls. Volatile constituents of the almond hulls have also been studied $[8,9]$.

The present study is conducted on the hulls of almonds collected from Kashgar area of China. Quantification of total polyphenolic compounds and total flavonoids were performed along with the identification of compounds through HPLC-MS/MS analysis in the 70\% ethanol extract. Furthermore, all the prepared extracts were evaluated for their antioxidant and antimicrobial activities.

\section{Materials and Methods}

2.1. Chemicals and Reagents. Quercetin (98\%), gallic acid $(\geq 97 \%)$, aluminium chloride, sodium acetate, Folin-Ciocalteu reagent $(2 \mathrm{~N}), \mathrm{DPPH}, \mathrm{EDTA}$, and vitamin $\mathrm{C}$ were purchased from Sigma-Aldrich $\mathrm{GmbH}$ (Steinheim). Absolute ethanol, methanol, hexane, chloroform, ethyl acetate, and $n$-butanol were procured from Tianjin Baishi Chemical Company (Pvt), Urumqi, China. All the chemicals and reagents were of analytical grade, and double-distilled water was used throughout the experiments.

2.2. Collection of the Almond Fruit. Almond fruits (Prunus dulcis) were obtained from an almond farm in Kashghar, China. The fruits were authenticated, and the voucher sample has been deposited in the herbarium of the Xinjiang Technical Institute of Physics and Chemistry, Chinese Academy of Sciences, Urumqi 830011, P. R. China. Hulls were removed and ground to powder with particle size 50300 mesh through a grinder (Model: 500A) from AO LI BANG, P. R. China.

2.3. Extraction. Almond hulls powder was extracted with $70 \%$ ethanol with the plant-to-solvent ratio of $1: 10$ for 24 hours at room temperature, and the extraction was repeated thrice. Combined extract was reduced to dryness under vacuum at $50^{\circ} \mathrm{C}$. The dried $70 \%$ ethanol extract was suspended in $500 \mathrm{ml}$ water and partitioned successively with hexane $(3 \times 500 \mathrm{ml})$, chloroform $(3 \times 500 \mathrm{ml})$, ethyl acetate $(3 \times 500 \mathrm{ml})$, and $n$-butanol $(3 \times 500 \mathrm{ml})$ producing hexane, chloroform, ethyl acetate, and $n$-butanol fractions. The remaining is the aqueous extract. Figure 1 shows the flow sheet diagram of extraction and fractionation of almond hulls powder.

2.4. Determination of Total Polyphenolic Compounds and Total Flavonoids. One gram of the dried $70 \%$ ethanol extract of almond hulls was reconstituted in $20 \mathrm{ml}$ of $70 \%$ methanol, and this extract was used for the determination of total polyphenolic compounds and total flavonoid contents. Folin-Ciocalteu method published in the literature $[10,11]$ was used for the estimation of total polyphenolic compounds as follows: FC reagent $(2 \mathrm{~N})$ was first diluted with water at a ratio of $1: 10$ and then $5 \mathrm{ml}$ of the diluted FC reagent was thoroughly mixed with $1 \mathrm{ml}$ of each of blank (water), extract, and the working standards solutions in test tubes separately. After 8 minutes of reaction, $4 \mathrm{ml}$ of $\mathrm{Na}_{2} \mathrm{CO}_{3}$ solution (7.5\%) was added to each mixture and mixed thoroughly. Samples were preserved for 2 hours at room temperature and kept away from strong light. Absorbance of these test solutions was read against the prepared blank at $740 \mathrm{~nm}$ by using a UV-visible spectrophotometer. Gallic acid was used as the reference standard, and working standards were prepared in the concentration range of $0.02 \mathrm{mg} / \mathrm{ml}$ to $0.2 \mathrm{mg} / \mathrm{ml}$ in water.

Total flavonoid contents were determined employing the method as stated in the published literature $[11,12] .1 \mathrm{~g}$ of the dried extract was reconstituted in $20 \mathrm{ml}$ of $70 \%$ ethanol and dried under vacuum. The obtained residue was dissolved in $10 \mathrm{ml}$ of methanol, and this solution was used for further experiment. $1.5 \mathrm{ml}$ of methanol was added to $0.5 \mathrm{ml}$ of each of the plant extract, working standard solutions, and the blank (methanol) in test tubes. Flavonoid-aluminium complex was prepared in extract/standard test tubes by successive addition of $10 \%$ aluminium chloride $(0.1 \mathrm{ml}), 1 \mathrm{M}$ potassium acetate $(0.1 \mathrm{ml})$, and distilled water $(2.8 \mathrm{ml})$. Solutions were thoroughly mixed at each step, and the absorbance of the reaction mixtures was measured after 30 minutes at $415 \mathrm{~nm}$ by using the UV-visible spectrophotometer. Working standard solutions of quercetin were prepared in the concentration range $0.01 \mathrm{mg} / \mathrm{ml}$ to $0.1 \mathrm{mg} /$ $\mathrm{ml}$ in methanol.

2.5. HPLC-MS/MS Analysis. Analysis of 70\% ethanol extract was performed on a linear ion-trap mass spectrometer (4000 Q TRAP) connected to the LC system through ESI interface from AB Sciex. Analyst 1.5 software was used to control LCESI-MS. The sample was chromatographed on a reversedphase column (XBridge $^{\mathrm{TM}} \mathrm{C} 18$, particle size $5 \mu \mathrm{m}$, $4.6 \times 150 \mathrm{~mm}$ with guard column). Mobile phase consisted of A ( $1 \%$ formic acid in water) and B (1\% formic acid in acetonitrile). Column temperature was kept as ambient, and a flow rate of $0.5 \mathrm{ml}$ per minute was used. Gradient elution was started at 5\% B and raised to $60 \% \mathrm{~B}$ in 30 minutes. The concentration of the mobile phase was changed to $100 \% \mathrm{~B}$ up to 35 minutes and hold at $100 \%$ B for 5 minutes. The whole analysis was completed in 40 minutes. MS was operated in negative ionization mode, and the scanning was performed in the $\mathrm{m} / z$ mass range values from 100 to 2000 . Twenty microliters $(20 \mu \mathrm{l})$ of the sample was injected into the chromatographic column.

2.6. Antioxidant and Antidiabetic Activities. The antioxidant activity of all the extracts on DPPH (1,1-diphenyl-2-picrylhydrazyl) was determined according to the procedure published in the literature $[13,14]$. The extracts were dissolved in DMSO in a concentration of $100 \mathrm{ppm}$. Sample solution $(2.5 \mathrm{ml})$ was added to a 96-microwell plate. One milliliter of $0.3 \mathrm{mM}$ DPPH solution in ethanol was added in each well to produce the test solutions. DMSO $(1 \mathrm{ml})$ was used as a blank solution. A negative control sample was prepared by mixing $1 \mathrm{ml}$ of DPPH solution with DMSO $(2.5 \mathrm{ml})$. Ascorbic acid (vitamin C) was used as the positive control in this assay. All the solutions were kept in the dark at room temperature for $30 \mathrm{~min}$. Absorbance was monitored 
Almond hulls powder $(2.5 \mathrm{~kg})$<smiles>C=CC=C</smiles>

Extraction with $70 \%$ ethanol for $24 \mathrm{hrs}$ at room temperature Repeated the extraction thrice

Combined all the extracts and reduced to dryness under vacuum at $50^{\circ} \mathrm{C}$

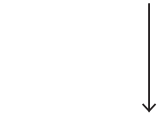

$70 \%$ ethanol extract $(184 \mathrm{~g})$<smiles>C1CCCCC1</smiles>

Suspended in water and partitioned as follows

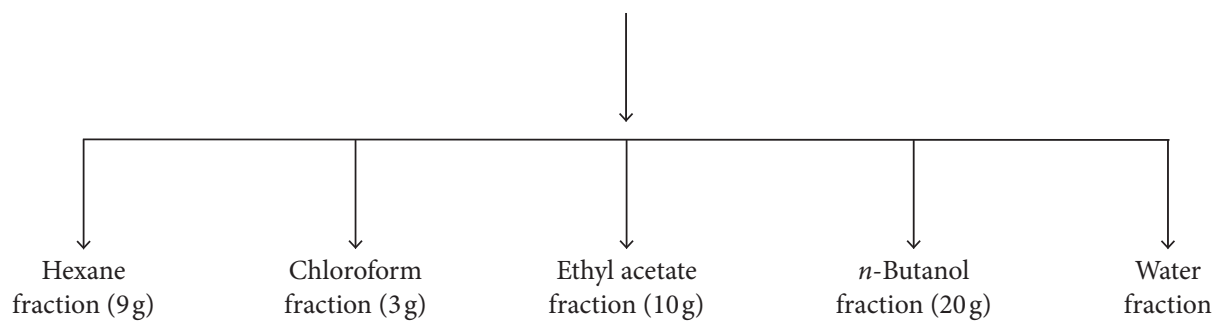

Figure 1: Flow sheet diagram of extraction and fractionation of almond hulls powder.

at a wavelength of $517 \mathrm{~nm}$, and the half maximal inhibitory concentration $\left(\mathrm{IC}_{50}\right)$ was calculated using the observed absorbance values.

Antidiabetic activity of all the extracts was determined using the PTP1B enzyme inhibition assay according to the procedure published in the literature [15]. Test sample was prepared by dissolving $0.1 \mathrm{~g}$ of the dried extract in $1 \mathrm{ml}$ of DMSO. $1 \mathrm{ml}$ of the PTP1B protein solution $(0.115 \mathrm{mg} / \mathrm{mL})$ and $1 \mu \mathrm{l}$ of the test sample/positive control sample/DMSO were added to the 96-well plate containing $178 \mu \mathrm{l}$ of buffer solution [20 mM HEPES (4-(2-hydroxyethyl)-1-piperazine ethanesulfonic acid), $150 \mathrm{mM} \mathrm{NaCl}$, and $1 \mathrm{mM}$ EDTA (ethylenediaminetetraacetic acid)] and mixed them well. The 96-well plate was incubated at room temperature for $10 \mathrm{~min}$, and then $20 \mu \mathrm{l}$ of pNPP solution $(35 \mathrm{mM})$ was added. After 30 minutes of reaction in dark at $25^{\circ} \mathrm{C}, 10 \mu \mathrm{l}$ of $3 \mathrm{M} \mathrm{NaOH}$ solution was mixed. The absorbance was determined at $405 \mathrm{~nm}$ wavelength using SpectraMax MD5 (Molecular Devices, USA) and was corrected by measuring the increase in absorbance at $405 \mathrm{~nm}$ of the sample from the nonenzymatic hydrolysis of $35 \mathrm{mM}$ pNPP obtained in the absence of PTP1B enzyme. Inhibition percentage (\%) and $\mathrm{IC}_{50}$ value were calculated. PTP1B inhibitor was used as a control sample.

2.7. Antimicrobial Activity. Antimicrobial activities of the crude extracts were measured using the agar well diffusion method [16, 17]. Fungal and bacterial pathogens: Candida albicans (CA; ATCC10231), E. coli (EC; ATCC11229), and Staphylococcus aureus (SA; ATCC6538), were used as indicator strains for this analysis using ampicillin sodium salt and amphotericin B as standards [18]. These microorganisms were aseptically inoculated into appropriate liquid media and incubated at $37^{\circ} \mathrm{C}$. After $16 \mathrm{~h}$, the cells were centrifuged at $6000 \mathrm{rpm}$ for $10 \mathrm{~min}$ and then suspended in sterile water. The different cells $(1 \mathrm{ml})$ were added to appropriate agar media $(100 \mathrm{ml})$ prior to plating, and the wells were made using an agar well borer. To these wells, extracts having $100 \mathrm{ppm}$ concentrations were added and subsequently incubated at $37^{\circ} \mathrm{C}$ for $24 \mathrm{~h}$. Zone of inhibitions were estimated by measuring the diameter of the microbial growth inhibition zone. Values were averaged from three independent experiments.

\section{Results and Discussion}

3.1. Total Polyphenolic Compounds and Total Flavonoid Contents. Total polyphenolic compounds were calculated as gallic acid equivalent using the regression equation obtained from the calibration curve with an $R^{2}$ value of 0.9956 (Figure 2). The values obtained from triplicate experiments were averaged resulting in the total amount of poyphenolic compounds as gallic acid equivalents as $1 \% \mathrm{w} / \mathrm{w}$ of the dried extract.

Total flavonoid contents were quantified through the procedure of reacting $\mathrm{AlCl}_{3}$ with the free flavonoids present in the extract, resulting in the Al-flavonoid complex 


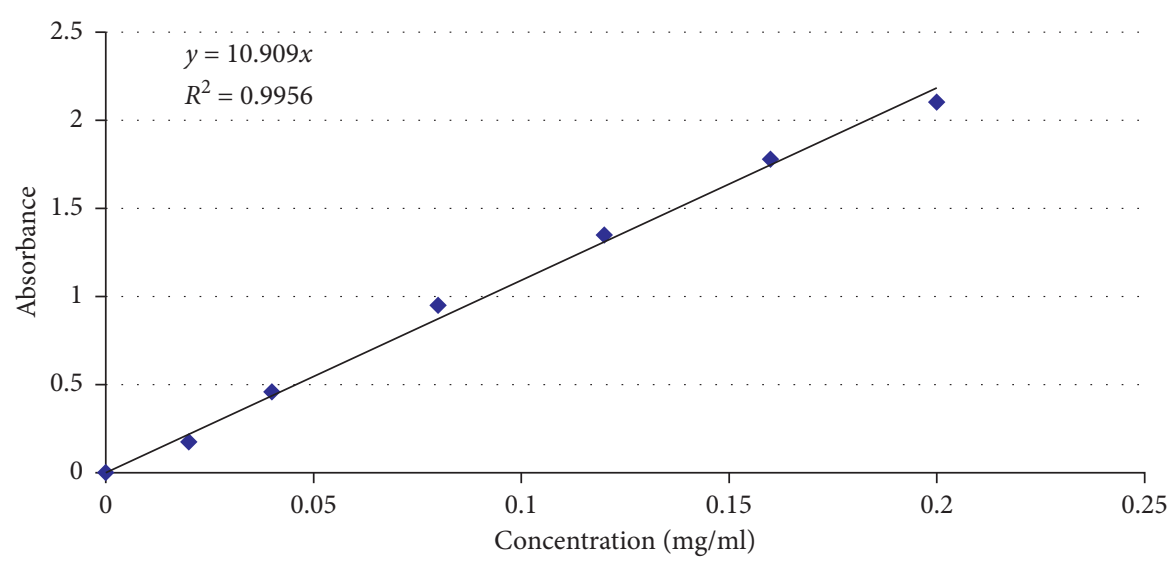

FIGURE 2: Calibration curve of gallic acid for the determination of total polyphenolic compounds.

formation with an absorption maximum at $415 \mathrm{~nm}$. MS Excel sheet was used for constructing the calibration curve after observing the absorbance of the quercetin standard solutions in the range of $0.01 \mathrm{mg} / \mathrm{mL}$ to $0.1 \mathrm{mg} / \mathrm{mL}$ in methanol at $415 \mathrm{~nm}$ (Figure 3). Calibration curve with an $R^{2} 0.9971$ was obtained, and the experiment was repeated three times. This delivered an averaged value for the total flavonoid contents as quercetin equivalents as $0.2 \% \mathrm{w} / \mathrm{w}$ of the dried extract.

3.2. HPLC-MS/MS Analysis. Total ion chromatogram has been shown as Figure 4, while Table 1 shows the compounds identified in the $70 \%$ ethanol extract of almond hulls through LC-MS/MS analysis along with their peaks retention times, fragmentation pattern, and the references. The names of the compounds to the peaks were assigned based on matching the obtained fragmentation pattern of the analytes at the given retention time with those published in the literature as cited.

Protocatechuic acid gave a peak at $9.273 \mathrm{~min}$ with [M-H] $]^{-}$ion at the $\mathrm{m} / z$ value 153 with an $\mathrm{MS}^{2}$ fragment at $\mathrm{m} / z 109$ due to the loss of mass unit 44 , which may be due to the removal of $\mathrm{CO}_{2}$ from pseudomolecular ion [M-H$\left.\mathrm{CO}_{2}\right]^{-}$. Signals at $10.051,10.687$, and $13.658 \mathrm{~min}$ with [M-H] $]^{-}$ion at the $m / z$ value 577 gave fragmentation pattern similar to the (epi)catechin dimer as confirmed from the literature. The fragmentation pattern consisting of the main fragments at the $m / z$ value 451 is due to heterocyclic ring fission $\left[\mathrm{M}-\mathrm{C}_{6} \mathrm{H}_{6} \mathrm{O}_{3}-\mathrm{H}\right]^{-}, 425$ is due to retro-Diels-Alder cleavage $\left[\mathrm{M}-\mathrm{C}_{8} \mathrm{H}_{8} \mathrm{O}_{3}-\mathrm{H}\right]^{-}, 407$ is due to subsequent dehydration $\left[\mathrm{M}-\mathrm{C}_{8} \mathrm{H}_{8} \mathrm{O}_{3}-\mathrm{H}_{2} \mathrm{O}-\mathrm{H}\right]^{-}$, and 289 which is due to $\left[\mathrm{M}_{(\text {epi)catechin }}-\mathrm{H}\right]^{-}$.

Trimeric (epi)catechin appeared at 10.616 with $[\mathrm{M}-\mathrm{H}]^{-}$ ion at the $m / z$ value 865 . Main fragments in the fragmentation pattern are as follows: at $m / z$ value $738\left[\mathrm{M}-\mathrm{C}_{6} \mathrm{H}_{6} \mathrm{O}_{3}-\right.$ $\mathrm{H}]^{-}, 713\left[\mathrm{M}-\mathrm{C}_{8} \mathrm{H}_{8} \mathrm{O}_{3}-\mathrm{H}\right]^{-}$, and $695\left[\mathrm{M}-\mathrm{C}_{8} \mathrm{H}_{8} \mathrm{O}_{3}-\mathrm{H}_{2} \mathrm{O}-\mathrm{H}\right]^{-}$ and interflavanic bond breakage producing ions at $\mathrm{m} / z 577$ and 289. Peaks at 11.099, 28.821, and 29.672 minutes were attributed to (epi)catechin with $[\mathrm{M}-\mathrm{H}]^{-}$ion at the $m / z$ value 289. Chlorogenic acid with $[\mathrm{M}-\mathrm{H}]^{-}$ion at the $m / z$ value 353 arose at $11.704 \mathrm{~min}$, showing a fragment ion at $\mathrm{m} / z 335$ due to the removal of water molecule. Peak at 22.167 min was assigned to 3-prenyl-4-O- $\beta$-glucopyranosyl oxy-4-hydroxy benzoic acid with $[\mathrm{M}-\mathrm{H}]^{-}$ion at the $m / z$ value 367 . Based on the $[\mathrm{M}-\mathrm{H}]^{-}$ions and their fragmentation pattern, peaks at $13.048 \mathrm{~min}$ and $14.893 \mathrm{~min}$ were assigned to kaempferol rhamnoside and kaempferol glucoside, respectively. Isorhamnetin rutinoside and isorhamnetin gave signals at $16.119 \mathrm{~min}$ and $16.187 \mathrm{~min}$.

The peak at 20.207 min gave a fragmentation pattern that of singly hydrated chlorogenic acid. $[\mathrm{M}-\mathrm{H}]^{-}$ion at the $\mathrm{m} / \mathrm{z}$ value 371 was due to hydrated molecule of chlorogenic acid, which lost a mass of $18 \mathrm{~m}$.u. (water molecule) producing a signal for the $\mathrm{m} / z$ value 353 , which is that of chlorogenic acid. Kaempferol showed a peak at 21.258 while (epi)catechin dihydrated molecules showed a peak at 23.085 and $26.093 \mathrm{~min}$, showing signal at the $\mathrm{m} / \mathrm{z}$ value 325 , which on successive lose of 18 m.u., producing signals at 307 and 289. Mono hydrated (epi)catechin appeared at 26.02, 26.582, and $29.725 \mathrm{~min}$. The peak at $31.371 \mathrm{~min}$ was assigned to ursolic acid with $[\mathrm{M}-\mathrm{H}]^{-}$ion at 455 , while peaks at 37.803 and 39.084 min gave a fragmentation pattern similar to that of amygdalactone, producing $[\mathrm{M}-\mathrm{H}]^{-}$ion at $m / z 295$.

All the compounds shown in the table have already been identified in the almond hulls except dimeric, trimeric, and hydrated (epi)catechin derivatives. Among the three triterpenoids such as betulinic acid, oleanolic acid, and ursolic acid which have been identified previously in the almond hulls, we could only identify ursolic acid in our study. Ursolic acid has shown various pharmacological activities such as antitumor, anti-inflammatory, antihyperlipidemic, anti-HIV, and hepatoprotective $[2,6]$.

\subsection{Pharmacological Activities}

3.3.1. Antioxidant Activity. DPPH is a stable radical and mostly employed for the evaluation of antioxidant activity. It has a characteristic absorption at the wavelength $517 \mathrm{~nm}$, which decreases when exposed to some radical scavengers. Lower absorption at the wavelength $517 \mathrm{~nm}$ delivers lower $\mathrm{IC}_{50}$ value indicating stronger activity. Antioxidant activities of the seven samples/extracts were tested using the DPPH assay procedure. All the samples showed very low antiradical activity as compared to the standard used as vitamin $\mathrm{C}$ with 


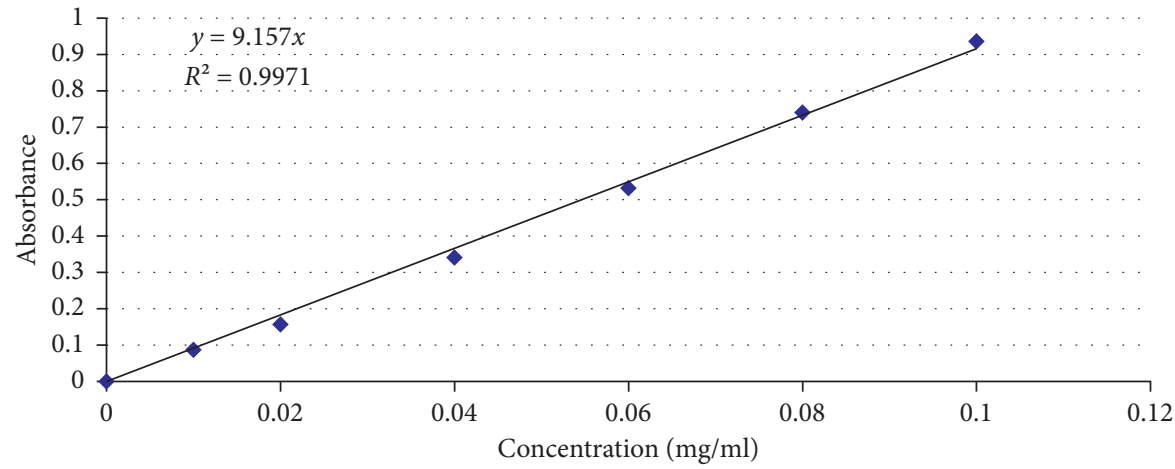

Figure 3: Calibration curve of quercetin for the determination of total flavonoid contents.

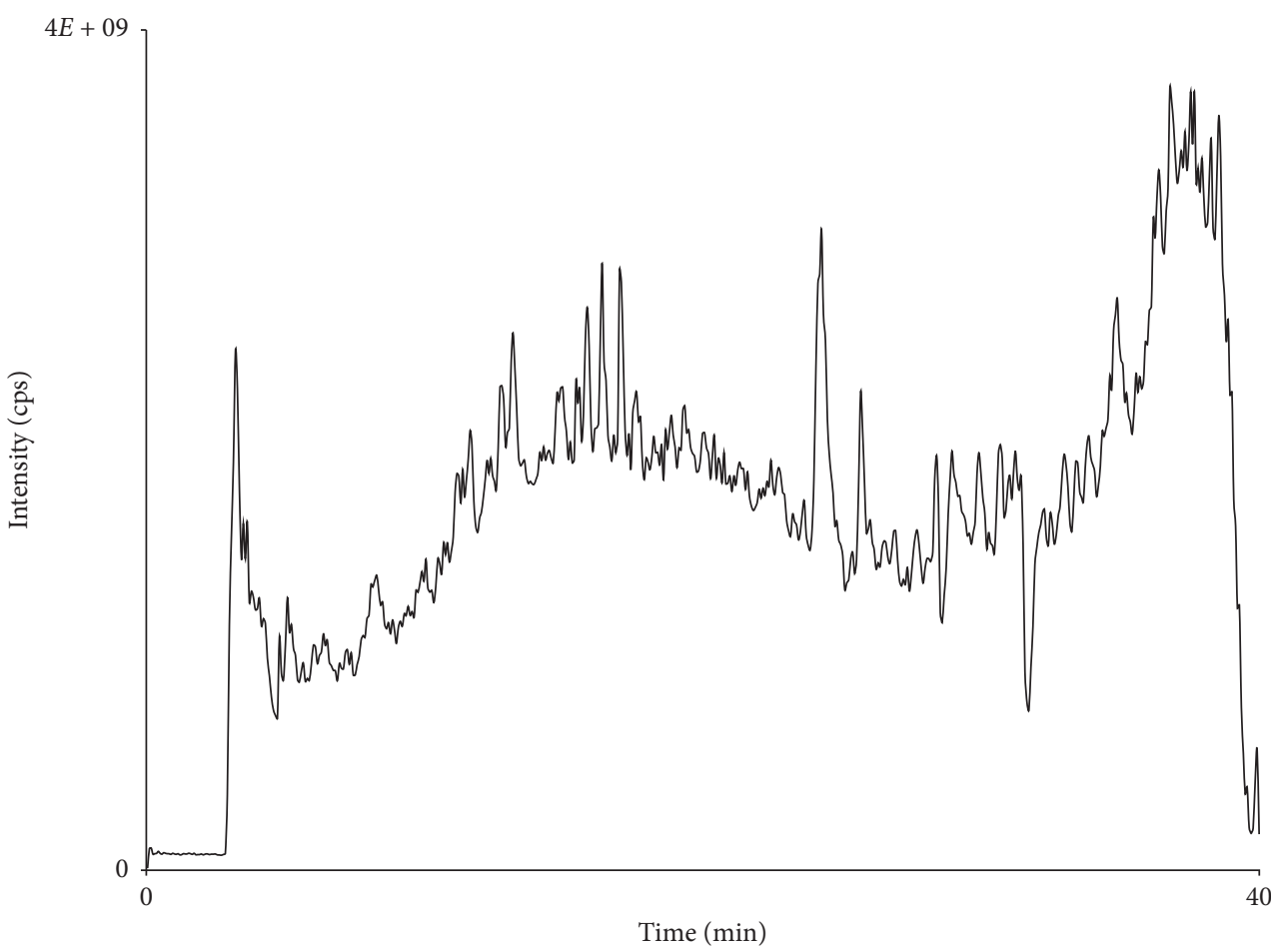

FIGURE 4: Total ion chromatogram of the $70 \%$ ethanolic extract of almond hulls.

TABLE 1: Results of the LC-MS/MS analysis of the 70\% ethanol extract of almond hulls.

\begin{tabular}{|c|c|c|c|c|}
\hline No & $\mathrm{RT}(\min )$ & Fragmentation pattern & Name & Reference \\
\hline 1 & 9.273 & $152.9,109$ & Protocatechuic acid (dihydroxybenzoic acid) & {$[6]$} \\
\hline 2 & $\begin{array}{l}10.051,10.687 \\
13.658\end{array}$ & $577.2,451,439,425,407,289.2$ & (epi)Catechin-(epi)catechin & {$[15]$} \\
\hline 3 & 10.616 & $865.3,739,713,695,577,451.2,425,407,289.1$ & (epi)Catechin-(epi)catechin-(epi)catechin & {$[15]$} \\
\hline 4 & $\begin{array}{l}11.099,28.821 \\
29.672\end{array}$ & 289.1 & Catechin & {$[6]$} \\
\hline 5 & 11.704 & $353.1,335.3$ & Chlorogenic acid & {$[1]$} \\
\hline 6 & 13.048 & $431.3,285.2$ & Kaempferol rhamnoside & {$[7]$} \\
\hline 7 & 16.119 & $623.4,315.1,299$ & Isorhamnetin rutinoside & [15] \\
\hline 8 & 16.187 & $315.2,297.4$ & Isorhamnetin & [15] \\
\hline 9 & 20.207 & $371.2,353.2$ & Chlorogenic acid monohydrated & [19] \\
\hline 10 & 21.258 & 284.9 & Kaempferol & {$[7]$} \\
\hline 11 & 22.167 & $367.1,352,336.2,321.1,306.2,277.8$ & $\begin{array}{c}\text { 3-Prenyl-4-O- } \beta \text {-glucopyranosyl oxy-4-hydroxy } \\
\text { benzoic acid }\end{array}$ & {$[6]$} \\
\hline 12 & $23.085,26.093$ & $325.2,307,289.2$ & (epi)Catechin dihydrated & {$[20]$} \\
\hline 13 & $26.02,26.582,29.725$ & $307.3,289.1$ & (epi)Catechin monohydrated & {$[20]$} \\
\hline 14 & 31.371 & 455.2 & Ursolic acid & {$[6]$} \\
\hline 15 & $37.803,39.084$ & $295.2,277.1$ & Amygdalactone & [21] \\
\hline
\end{tabular}


Table 2: Antioxidant and antidiabetic activities of Prunus dulcis hull extracts.

\begin{tabular}{lcc}
\hline Sample & Antioxidant activity $\mathrm{IC}_{50}(\mu \mathrm{g} / \mathrm{ml})$ & ${\text { Antidiabetic activity } \mathrm{IC}_{50}(\mu \mathrm{g} / \mathrm{ml})}^{\text {Inactive }}$ \\
\hline $70 \%$ ethanol extract & 167.11 & $9.66 \pm 0.42$ \\
Hexane fraction & $>500$ & $37.95 \pm 0.14$ \\
Chloroform fraction & 128.17 & Inactive \\
Ethyl acetate fraction & 148.32 & Inactive \\
$n$-Butanol fraction & 76.04 & Inactive \\
Water fraction & $>500$ & - \\
Vitamin C & $5.34 \pm 0.42(\mu \mathrm{g} / \mathrm{ml})$ & $1.46 \pm 0.40$ \\
PTP1B inhibitor & - & \\
\hline
\end{tabular}

an $\mathrm{IC}_{50}$ value $5.34 \mu \mathrm{g} / \mathrm{ml}$ (Table 2). Among the samples, $n$ butanol fraction showed highest activity with $\mathrm{IC}_{50}$ value $76.04 \mu \mathrm{g} / \mathrm{ml}$. $\mathrm{IC}_{50}$ values of chloroform, ethyl acetate, and $70 \%$ ethanol extracts were $128.17,148.32$, and $167.11 \mu \mathrm{g} / \mathrm{ml}$, respectively. $\mathrm{IC}_{50}$ values of the hexane and water fractions were beyond $500 \mu \mathrm{g} / \mathrm{ml}$.

3.3.2. Antidiabetic Activity. Antidiabetic activity was determined using the protein tyrosine phosphatase-1B (PTP1B) inhibition procedure. Hexane and chloroform fractions showed antidiabetic (PTP1B inhibition) activity with an $\mathrm{IC}_{50} 9.66 \mu \mathrm{g} / \mathrm{ml}$ and $37.95 \mu \mathrm{g} / \mathrm{ml}$, respectively (Table 2). PTP1B inhibitor showed inhibition with an $\mathrm{IC}_{50}$ $1.46 \mu \mathrm{g} / \mathrm{ml}$. Remaining extracts were inactive.

3.3.3. Antibacterial Activities. All the seven samples were screened against the three microbial strains: Candida albicans (CA; ATCC10231; fungus), Escherichia coli (EC; ATCC11229; gram-negative bacteria), and Staphylococcus aureus (SA; ATCC6538; gram-positive bacteria) using ampicillin sodium salt and amphotericin $B$ as standards. No any extract showed activity against the $\mathrm{CA}$ and $\mathrm{EC}$, while hexane and chloroform fractions delivered activity against the SA with the zone of inhibition diameters $9 \mathrm{~mm}$ and $12 \mathrm{~mm}$, respectively, in comparison with the standard ampicillin sodium salt, which yielded $19 \mathrm{~mm}$ inhibition zone diameter.

\section{Conclusion}

These analyses confirmed that the almond waste, i.e., hulls, is a rich source of pharmacological active metabolites, based on which the hulls can be used in various pharmaceutical preparations. Furthermore, the use of hulls for obtaining these chemicals can also reduce the cost incurred on the wastage of these hulls for those industries producing almond-based products.

\section{Data Availability}

The chemical analysis and pharmacological evaluation data of the shells of Prunus dulcis nuts used to support the findings of this study are included within the article.

\section{Conflicts of Interest}

The authors declare that there are no conflicts of interest on the publication of this paper.

\section{Acknowledgments}

This study was funded by the Projects of the International Cooperation and Exchange of the National Natural Science Foundation of China (Grant no. 31110103908), President's International Fellowship Initiative (Grant no. 2019PB0043), and the Central Asian Drug Discovery and Development Centre of Chinese Academy of Sciences (Grant no. CAM 201808). The authors acknowledge the Chinese Academy of Sciences for providing postdoctoral fellowships during the course of study.

\section{References}

[1] M. Rubilar, M. Pinelo, C. Shene, J. Sineiro, and M. J. Nuñez, "Separation and HPLC-MS identification of phenolic antioxidants from agricultural residues: almond hulls and grape pomace," Journal of Agricultural and Food Chemistry, vol. 55, no. 25, pp. 10101-10109, 2007.

[2] V. Amico, V. Barresi, D. Condorelli, C. Spatafora, and C. Tringali, "Antiproliferative terpenoids from almond hulls (Prunus dulcis): identification and structure-activity relationships," Journal of Agricultural and Food Chemistry, vol. 54, no. 3, pp. 810-814, 2006.

[3] A. Meshkini, "Acetone extract of almond hulls provides protection against oxidative damage and membrane protein degradation," Journal of Acupuncture and Meridian Studies, vol. 9, no. 3, 2016.

[4] N. Thebo, A. Simair, W. Sheikh, and A. AR, "Clinical study of the Prunus dulcis (almond) shell extract on Tinea capitis infection," Natural Products Chemistry \& Research, vol. 2, no. 3, p. 2, 2014.

[5] G. R. Takeoka and L. T. Dao, "Antioxidant constituents of almond [Prunus dulcis (Mill.) DA Webb] hulls," Journal of Agricultural and Food Chemistry, vol. 51, no. 2, pp. 496-501, 2003.

[6] S. Sang, K. Lapsley, R. T. Rosen, and C.-T. Ho, "New prenylated benzoic acid and other constituents from almond hulls (Prunus amygdalus Batsch)," Journal of Agricultural and Food Chemistry, vol. 50, no. 3, pp. 607-609, 2002.

[7] S. Frison and P. Sporns, "Variation in the flavonol glycoside composition of almond seedcoats as determined by MALDITOF mass spectrometry," Journal of Agricultural and Food Chemistry, vol. 50, no. 23, pp. 6818-6822, 2002.

[8] R. G. Buttery, R. M. Seifert, W. F. Haddon, and R. E. Lundin, "2Hexyl-3-methylmaleic anhydride: an unusual volatile component of raisins and almond hulls," Journal of Agricultural and Food Chemistry, vol. 28, no. 6, pp. 1336-1338, 1980.

[9] R. G. Buttery, E. L. Soderstrom, R. M. Seifert, L. C. Ling, and W. F. Haddon, "Components of almond hulls: possible navel 
orangeworm attractants and growth inhibitors," Journal of Agricultural and Food Chemistry, vol. 28, no. 2, pp. 353-356, 1980.

[10] M. N. Qureshi, G. Stecher, and G. K. Bonn, "Determination of total polyphenolic compounds and flavonoids in Juglans regia leaves," Pakistan Journal of Pharmaceutical Sciences, vol. 27, no. 4, pp. 865-869, 2014.

[11] L. Jiang, S. Numonov, K. Bobakulov, M. Qureshi, H. Zhao, and H. Aisa, "Phytochemical profiling and evaluation of pharmacological activities of Hypericum scabrum L.," Molecules, vol. 20, no. 6, pp. 11257-11271, 2015.

[12] S. R. Numonov, M. N. Qureshi, and H. A. Aisa, "Development of HPLC protocol and simultaneous quantification of four free flavonoids from Dracocephalum heterophyllum Benth," International Journal of Analytical Chemistry, vol. 2015, Article ID 503139, 5 pages, 2015.

[13] Y. Zhao, J. Dou, T. Wu, and H. Aisa, "Investigating the antioxidant and acetylcholinesterase inhibition activities of Gossypium herbaceam," Molecules, vol. 18, no. 1, pp. 951-962, 2013.

[14] H. Imam, R. Kasimu, and H. A. Aisa, "Analysis on the chemical components and antioxidant activity of volatile oil from Fructus ocimi basilici," Medicinal Plant, vol. 3, pp. 11-14, 2012.

[15] M. N. Qureshi, S. Numonov, A. Abudurexiti, and H. A. Aisa, "Phytochemical investigations and evaluation of antidiabetic potential of Prunus dulcis nuts," LWT-Food Science and Technology, vol. 66, pp. 311-317, 2016.

[16] J. Lin, J. Dou, J. Xu, and H. A. Aisa, "Chemical composition, antimicrobial and antitumor activities of the essential oils and crude extracts of Euphorbia macrorrhiza," Molecules, vol. 17, no. 5, pp. 5030-5039, 2012.

[17] K. Bozorov, B. Elmuradov, K. Shakhidoyatov, H. A. Aisa, and B. Tashkhodjaev, "2,3-trimethylene-7,8-dihydropyrrolo [1,2a]thieno [2,3-d]pyrimidin-4(6H)-one," Acta Crystallographica Section E: Structure Reports Online, vol. 69, no. 8, p. 1224, 2013.

[18] K. Bozorov, H.-R. Ma, J.-Y. Zhao et al., "Discovery of diethyl 2,5-diaminothiophene-3,4-dicarboxylate derivatives as potent anticancer and antimicrobial agents and screening of antidiabetic activity: synthesis and in vitro biological evaluation. Part 1," European Journal of Medicinal Chemistry, vol. 84, pp. 739-745, 2014.

[19] N. Dartora, L. M. de Souza, A. P. Santana-Filho et al., "UPLCPDA-MS evaluation of bioactive compounds from leaves of Ilex paraguariensis with different growth conditions, treatments and ageing," Food Chemistry, vol. 129, no. 4, pp. 1453-1461, 2011.

[20] H. Martins, J. P. Leal, M. T. Fernandez, V. H. C. Lopes, and M. N. D. S. Cordeiro, "Toward the prediction of the activity of antioxidants: experimental and theoretical study of the gasphase acidities of flavonoids," Journal of the American Society for Mass Spectrometry, vol. 15, no. 6, pp. 848-861, 2004.

[21] S. Sang, X. Cheng, H.-Y. Fu et al., "New type sesquiterpene lactone from almond hulls (Prunus amygdalus Batsch)," Tetrahedron Letters, vol. 43, no. 14, pp. 2547-2549, 2002. 

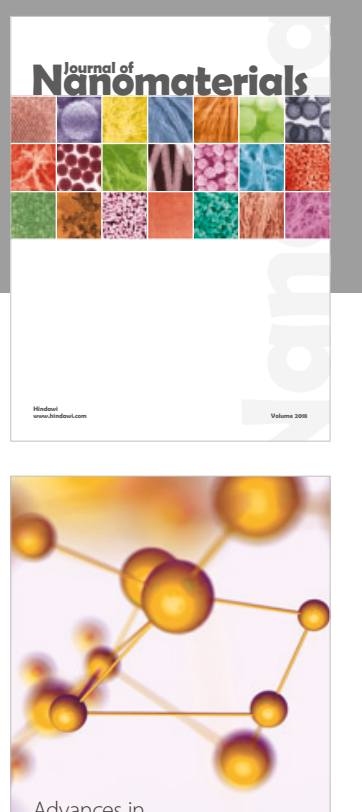

Physical Chemistry
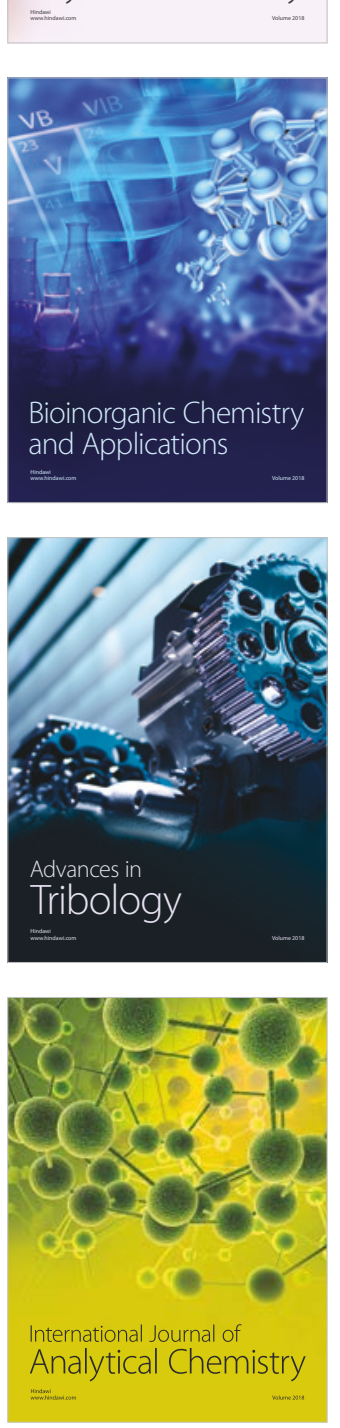

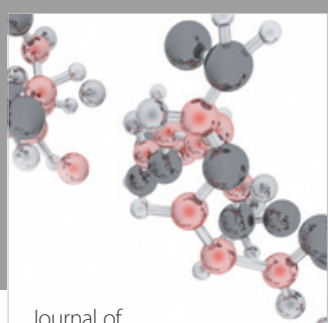

Analytical Methods

in Chemistry

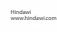

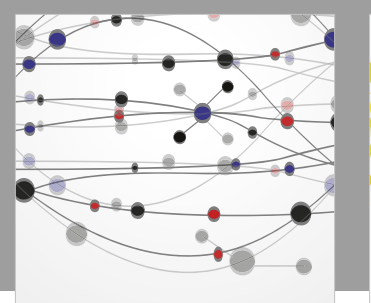

The Scientific World Journal

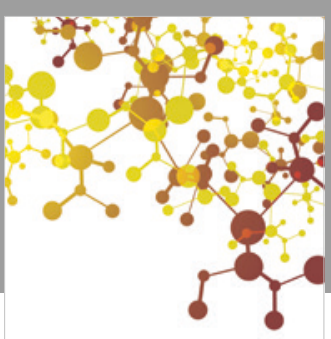

Journal of

Applied Chemistry
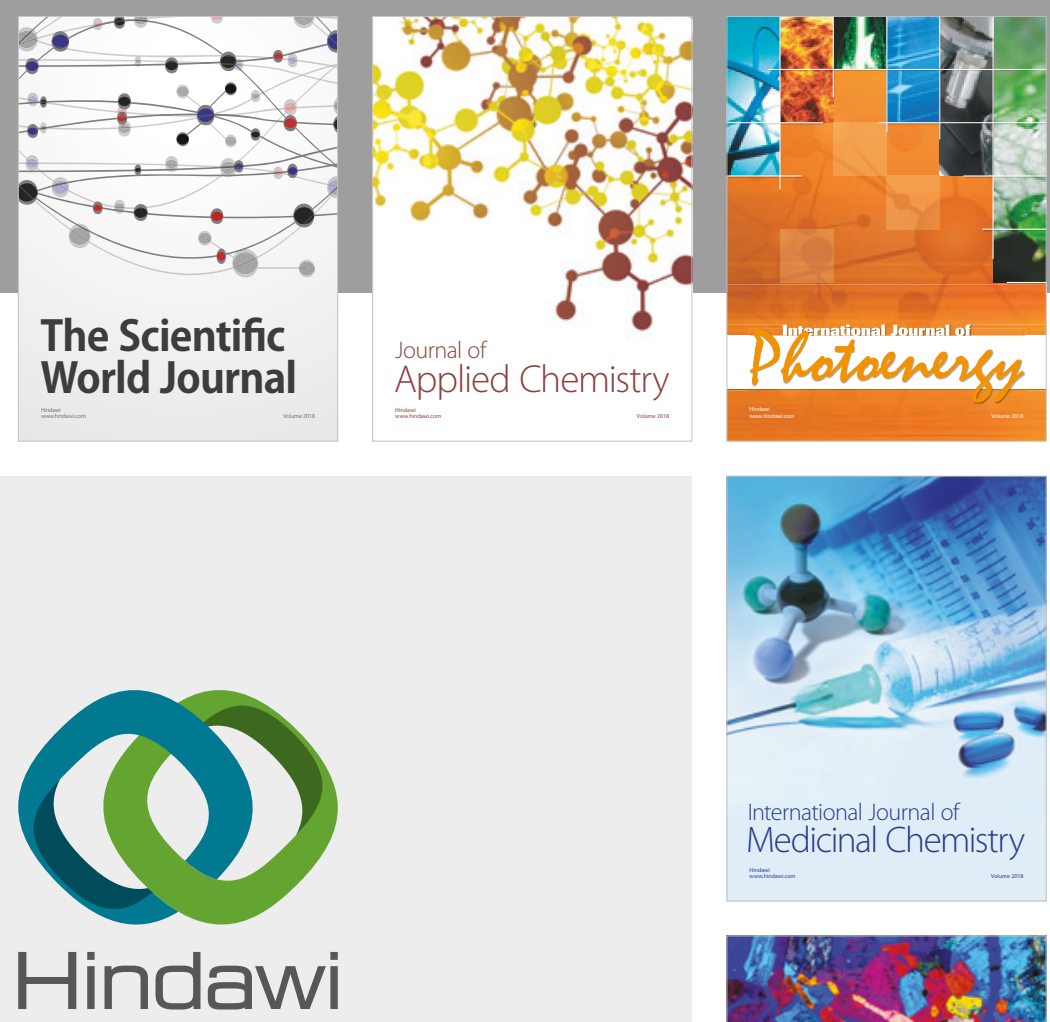

Submit your manuscripts at

www.hindawi.com
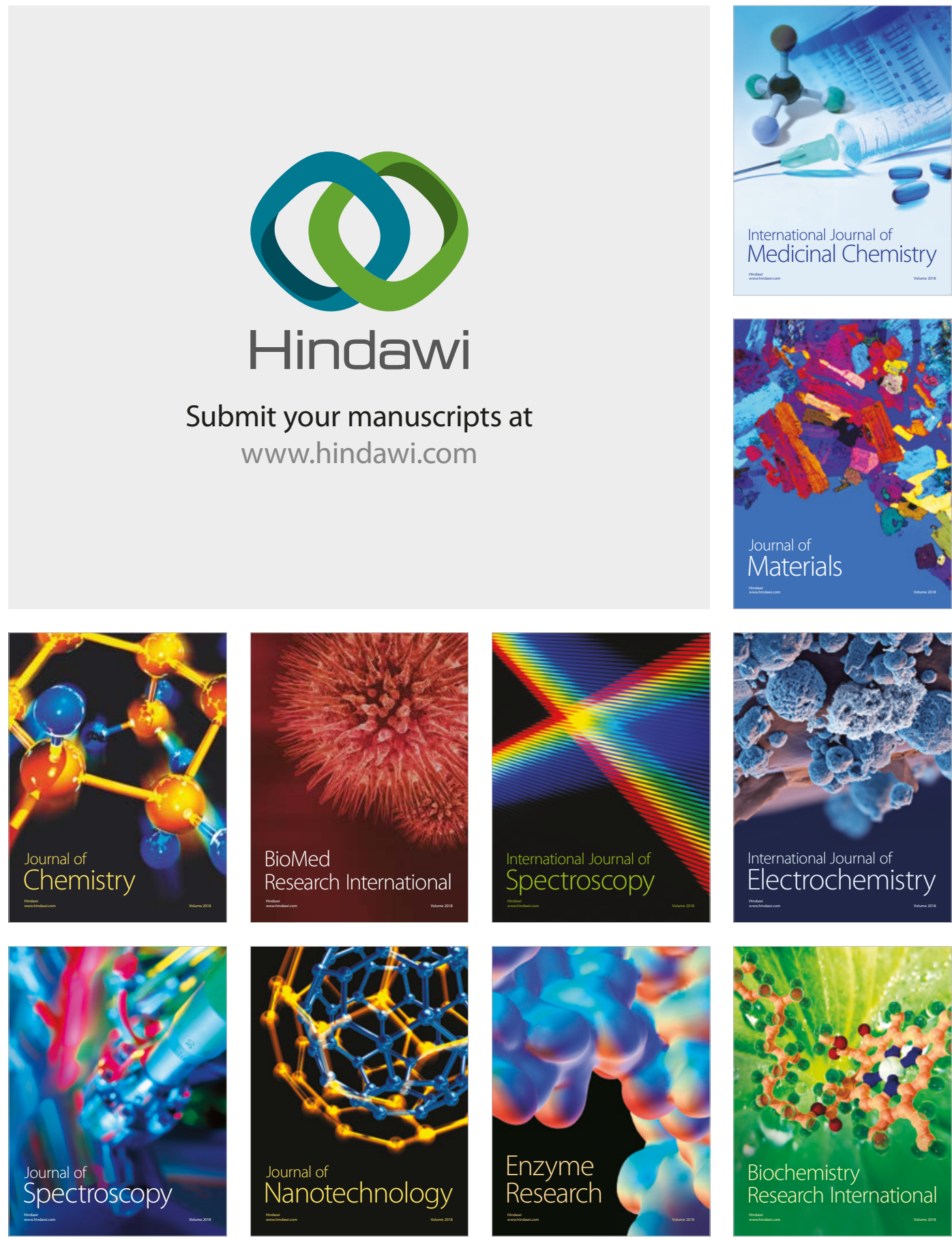
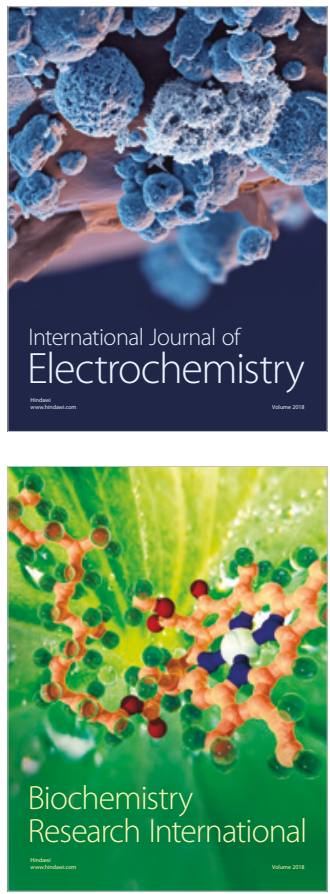